\title{
Intensive teaching technology of imported rabbit meat in Uzbekistan
}

\author{
$A$ Kholmatov ${ }^{1}, O$ Mamadiev $^{1}, U$ Soatov $^{1, *}, B$ Shayusupov ${ }^{1}, U$ Makhsudov $^{1}$, and $K$ Sattorov $^{1}$ \\ ${ }^{1}$ Tashkent State Agrarian University, University str., 2, Tashkent province, Uzbekistan, 100140
}

\begin{abstract}
One of the urgent problems is the development of modern technologies for the care and feeding of rabbits imported to the country on farms and households. This article provides scientific recommendations for feeding imported rabbits on farms and households on the basis of rations enriched with valuable macro and micro elements and vitamins. Feeding rabbits on the basis of complete rations, taking into account the nutritional norms, is important in the emergence of the genetic potential of the New Zealand rabbit breed.
\end{abstract}

\section{Introduction}

One of the important issues is to meet the growing needs of the population in livestock products, including meat. At present, in Europe and Asia, great attention is paid to the provision of the population with dietary meat products $[1,2]$.

By the decision of the Cabinet of Ministers in 2016, 10,000 female New Zealand rabbits were imported from Italy and rabbit farms were established in all regions of the country, and rabbits of this breed were raised on an industrial basis and high-quality dietary meat was produced.

At present, rabbit farms are being established and special attention is being paid to the development of the industry [3]. Along with increasing the production of dietary rabbit meat and providing workers with cheap meat in kitchens, new rabbit farms have been established in a number of districts and rabbit meat production is developing rapidly [4]. Rabbit meat is good for health and differs from other meats by its taste and dietary properties. The ability to use fresh frozen rabbit meat in all seasons enhances its dietary properties $[4,5]$.

Protein content is higher than mutton, beef, and pork. In terms of vitamin and mineral content, rabbit meat is superior to almost all types of meat. Its vitamins C, B12, B6, PP and iron, phosphorus, cobalt, manganese, fluorine and potassium cannot be equated with any other meat [6].

Depending on the direction of production, rabbits are divided into two groups, namely meat and meat skins. In the meat direction, rabbits are slaughtered at 60-70 days of age, and in the meat-skin direction at 3-5 months of age [5]. Each mother rabbit can give birth to 5-6 times a year. This means $70-80 \mathrm{~kg}$ of meat and 25-30 pieces of quality leather. Today, every farmer must grow high-quality, competitive export-oriented products through the use

\footnotetext{
*Corresponding author: soatov1978@mail.ru
} 
of rational methods of management, the introduction of resource-saving technologies [6]. If we approach the issue from this point of view, it is important to develop rabbit breeding on farms and in households.

AP Lesnyak [7] noted that it is important to keep the microclimate parameters at home, depending on the season, $6.7-14.3 \%$ of fat rabbits up to 3 months of age and $7.0-19.7 \%$ of adults from 3 months of age.

AG Ageykin [8] found out that intensive feeding of rabbits with nutritious feed on a resource-efficient, mechanized and automated farm allows achieving a high level of profitability.

VN Aleksandrov [9] discovered that keeping and caring for rabbits under a shed equipped with a new type of cage batteries could increase the production and improve the quality of rabbit products, as well as increase the supply of rabbit products to the market by $28 \%$ and labor productivity by 1.7 times, as well as reducing construction costs, depreciation and energy sources.

According to T Ikramov [10], in the farms of the Republic are fed mainly for rabbit meat and fur. Rabbit fur occupies a significant place among the furs grown in all regions of the country. Because rabbit fur is light, beautiful and inexpensive, it is used to make children's coats and fur shoes. Consequently, its importance in the national economy is great. Rabbits mature and multiply rapidly. Therefore, in a short time it is possible to grow a lot of high-quality dietary rabbit meat. One mother rabbit can get $70-80 \mathrm{~kg}$ of meat and 25-30 pieces of fur per year.

$\mathrm{J}$ Kushakov [11] investigated that rabbits are very fertile, giving birth to an average of 5-6 or more children a year. The number of children is 6-12 at one birth, and in some cases up to 16 . Feeding and caring for rabbits has a big impact on their fertility. Well-fed rabbits reach sexual maturity at $2-2.5$ months of age, but experienced rabbit breeders prefer to breed rabbits at 4 months of age. Early escape leads to a rapid deterioration of the external signs of rabbits.

Fadillah et al. [12] claimed that the biological performance of rabbits, the rapid maturation of rabbits depends in many respects on their breed. Of course, the individual characteristics of rabbits, feeding and storage conditions should also be taken into account. It is known from the literature that rabbits gained weight rapidly when kept in a cage of 4, one died when kept in 6-8, underweight when kept in 10-12, the cost of death increased by 2.

In regards to NI Tinaev [13], fur rabbits need a lot of attention and the process of feeding them is based on a special diet. Special attention is paid to the technology of slaughter of rabbits and their processing, from their secondary products can be prepared meat, bone and blood flour as a necessary feed.

YU Zhitnikova [14] stated that rabbit farms should be established on dry lands that are not wet and damp. Whenever possible you should have all four of these components in place for launch to maximize profits. In general, the placement of rabbit farms near livestock farms is easy and convenient in many respects (water supply, transportation, food supply, etc.).

Belichovska et al. [15] noted that, according to her research and experiments, rabbits born in January, February, and March are stronger, more resilient, larger than at other times. Alternatively, it adapts quickly to external environmental conditions. Many advanced rabbit farms are now making a lot of money with little investment. Because it saves a lot of wood, nails, stone and other materials. As a result, rabbits will be cheaper and better quality. Keeping and feeding rabbits. Employees of rabbit farms need to know how many rabbits should be on the farm each month.

Suleman et al. [16] affirmed that the diet of chinchillas takes into account their live weight and age. For example, a mother chinchilla with a baby weighing 4-5 kg should be 
planned to be fed $15 \%$ more than others. Chinchillas need to be provided with adequate amounts of quality greens and mixed feeds; otherwise they can become barren and suffer a lot of damage. Rabbit farms need to stockpile an average amount of food per year for each chinchilla they have. If there are a lot of large-weight chinchillas on the farm, then the above mentioned nutrients should be accumulated $10-15 \%$ more.

A Kholmatov [17] included rabbit meat in the diet. Rabbit meat fully retains its taste and quality, both when canned and smoked. Therefore, the demand for rabbit meat in foreign countries is high. Children of newborn domestic rabbits will have 16 milk teeth, and after 5-7 days the surface will be covered with down (wool). In 10-14 days the eyes will open. After 17-21 days, they go out of their place of birth and start eating.

\section{Materials and methods}

The research was conducted in 2019 in the conditions of the farm "Syrdarya fluffy rabbits" in Mirzaabad district of Syrdarya region and the house of Isaev Gulomkadir in the house 7, 3rd street, Yunusabad district, Tashkent. The body composition of rabbits was assessed based on their grading requirements. In the study of reproductive characteristics were taken into account the breeding of rabbits, fertility, and viability of rabbits at 21 days and up to 20 days.

The growth and development of rabbit cubs was determined by the dynamics of their live weight gain. In doing so, they were calculated as absolute, average daily and relative growth. Meat productivity was calculated by slaughter mass (weight) and slaughter consumption. The chemical composition and energy value of rabbit meat was carried out on the basis of current methods [7,8].

Group I (control) on the basis of the current farm ration by sexual age: mother rabbits (n-8), rabbits - 88 heads. External dimensions, indices, live mass (weight), reproductive quality, milk yield, survival of children up to 21 days and 4 months were determined.

Group II (experiment) - on the basis of a complete diet 8 heads of mother rabbits, a total of 96 heads of rabbit chicks, blood tests were taken from 5 heads, growth and development were studied in 25 heads of rabbits, meat productivity was studied in 5 heads of rabbits. The cost-effectiveness of the experiment was also studied and applied to production.

The energy value of rabbit meat was determined by the calculation method. Rabbit meat on a 9-point scale was determined by tasting (eating and drinking) after boiling. Blood samples were taken from the ear vein for hematological and biochemical examinations. Erythrocytes and leukocytes were counted in $1 \mathrm{ml} 3$ of blood using Goryaev's chamber. The amount of hemoglobin in the blood was determined using a photoelectrocolometer "Sali" hemometer. Biochemical parameters of blood were determined [14]. The economic efficiency of rabbit meat production in different ways was determined by the "Methods for determining economic performance" $[2,17]$.

\section{Results and discussion}

In Uzbekistan, gray giant, chinchilla, white giant and other breeds of rabbits are bred for meat production. In order to develop rabbit breeding in the Republic, a New Zealand breed of rabbit, created in the United States, was imported from Italy. Weight gain in rabbits is one of the main biological factors, and the study of this indicator is important and fundamental in the science of zootechnics. Based on the feeding structure and physiological condition, a feeding ration was developed for control group rabbits and experimental group rabbits (Tables 1 and 2). 
Table 1. Ration content of rabbits in the experimental group, $\%$.

\begin{tabular}{|c|c|c|c|c|}
\hline \multirow{2}{*}{ Types of feed } & \multicolumn{4}{|c|}{ Phases } \\
\cline { 2 - 5 } & Usual & Pregnancy & Lactation & Young grower \\
\hline Flour of alfalfa & 40 & 40 & 25 & 25 \\
\hline Corn bean & 20 & 20 & 27 & 27 \\
\hline Barley bean & 20 & 20 & 25 & 25 \\
\hline Wheat bean & 7 & 7 & 5 & 5 \\
\hline Soybean & 10 & 10 & 13 & 13 \\
\hline Mashed meat-bone & 2 & 2 & 4 & 4 \\
\hline Premix & 1 & 1 & 100 & 100 \\
\hline Total & 100 & 100 & & 1 \\
\hline
\end{tabular}

The composition of the feeding ration of experimental rabbits in the period of rest and calving of rabbits was $40 \%$ alfalfa, corn and barley grains $20 \%$, wheat grains $7 \%$, soybean meal $10 \%$, meat and bone meal $2 \%$, premixes $1 \%$. For young growing rabbits, a fullfledged ration of alfalfa hay $25 \%$, corn $27 \%$, barley $25 \%$, wheat $5 \%$, soybean meal $13 \%$, meat and bone meal $4 \%$, and premix $1 \%$ structure was constructed and experimental group rabbits were fed. The rabbits in the control group were based on a ration of available feed, ie $50 \%$ of alfalfa hay, $25 \%$ of corn and barley grains during the calving period, and the same during lactation and rearing of young rabbits.

Table 2. Ration content of rabbits in the control group, $\%$.

\begin{tabular}{|c|c|c|c|c|}
\hline \multirow{2}{*}{ Types of feed } & \multicolumn{4}{|c|}{ Phases } \\
\cline { 2 - 5 } & Usual & Pregnancy & Lactation & Young grower \\
\hline Flour of alfalfa & 50 & 50 & 50 & 50 \\
\hline Corn bean & 25 & 25 & 25 & 25 \\
\hline Barley bean & 25 & 25 & 25 & 25 \\
\hline Total & 100 & 100 & 100 & 100 \\
\hline
\end{tabular}

Table 2 shows that during the 150-day breeding period, the experimental group of rabbits consumed $2.28 \mathrm{~kg}$ less granular feed than the control group, $1.84 \mathrm{~kg}$ of dry matter, and $1.37 \mathrm{~kg}$ of fiber. It was observed that $0.78 \mathrm{~kg}$ of digestible protein and $0.02 \mathrm{~kg}$ of crude fat were consumed in excess.

Rabbits in the experimental group consumed $4.21 \mathrm{~kg}$ of feed unit, or $24.7 \%$ less than in the control group, to gain $1 \mathrm{~kg}$ of live weight. Experiments show that feeding rabbits on the basis of an accelerated full-value ration has a positive effect on reducing feed consumption and reducing the cost of the product.

Rabbits in the control and experimental groups were housed in single-layer wire cages measuring 2.0x1.0 inside the building under the same conditions, arranged according to a common group when feeding them. The mother rabbits were cared for individually in $70 \times 50 \times 50$ wire cages equipped with a 25 -seater birth nest. The water supply is done in a nipple system. Feeding was carried out individually in the form of granular feed three times a day. 
One of the main tasks of our experiment is to assess the adaptation of rabbit blood to the external environment, depending on the hematological and biochemical parameters, the hematological, biochemical parameters of the blood and its resistance (level of resistance) to the external environment. Table 3 shows the results obtained.

Table 3. Hematological parameters of rabbits $(n=5)$

\begin{tabular}{|c|c|c|c|}
\hline Parameters & Control & Experimental & Relative difference, \% \\
\hline Hemoglobin & 90.56 & 105.5 & 16.49 \\
\hline Erythrocytes & 7.85 & 8.34 & 6.24 \\
\hline Leukocytes & 6.43 & 6.98 & 9.06 \\
\hline
\end{tabular}

Blood plays an important role in metabolism in the body. Therefore, the study of rabbit blood analysis in our study is important and relevant.

When we analyzed the table, we found that the average hemoglobin level in the blood was $80.56 \mathrm{~g} / \mathrm{l}$ in the control group, while it was $16.49 \%$ higher on average in the rabbits in the experimental group fed on a full-value ration. We found that the amount of erythrocytes and leukocytes in the blood did not change significantly in both groups. All hematological parameters were found to be physiologically normal.

Based on the study of biochemical parameters of the blood of rabbits fed on a complete diet, it is possible to assess the metabolism of substances and minerals in their body. In the experimental group of rabbits, the total amount of protein in the blood was found to be on average $10.1 \%$ higher than in the control group. There was no significant difference in the mineral content of the blood between the groups. The ratio of calcium to phosphorus was found to be $1.061 \%$ in farm-fed rabbits and $2.021 \%$ in experimental rabbits fed a full-value ration (Table 4).

Table 4. Biochemical parameters of rabbit blood $(n=5)$.

\begin{tabular}{|c|c|c|}
\hline Parameters & Control & Experimental \\
\hline Total protein, \% & $96.06 \pm 16.23$ & $106.22 \pm 18.57$ \\
\hline Calcium, $\mathrm{mg} / \%$ & $11.52 \pm 1.31$ & $15.06 \pm 1.37$ \\
\hline Phosphorus, $\mathrm{mg} / \%$ & $7.10 \pm 0.131$ & $7.43 \pm 0.25$ \\
\hline Ratio $\mathrm{Ca} / \mathrm{P}$ & $1.06 / 1$ & $2.02 / 1$ \\
\hline Carotene, $\mathrm{mg} / \%$ & $0.86 \pm 0.06$ & $0.90 \pm 0.117$ \\
\hline
\end{tabular}

Thus, the process of protein and mineral metabolism in the blood of experimental rabbits shows that the control group is more active than in rabbits, which indicates a positive change in metabolism and vitality in the body of rabbits. When rabbits are fed on a full-value ration, their immunity is increased, leading to an increase in metabolism. Rabbits were inseminated at home at the age of 135 days, weighing not less than $4 \mathrm{~kg}$.

According to infertility of rabbits in the first group, the average number of newborn rabbits per 1 mother rabbit for the first time was 11 in the control group and 12 in the experimental group, of which 9 rabbits in the control group survived and 11 in the experimental group. The milk yield of rabbits was determined by weighing their young after each feeding.

Compared to the control group, the experimental group rabbits were found to have an average milk yield of 97.6 grams more. In the experimental group of rabbits fed on a fullvalue ration, the survival rate of young children up to 21 days of age was $97.8 \%$, while in the control group it was $93.5 \%$, which is $4.1 \%$ higher than in the experimental group. By age of 120 days, it was $96.6 \%$ in the experimental group and $92.2 \%$ in the control group. 
Thus, full-value feeding of rabbits was found to have a positive effect on their fertility performance (Table 5).

Table 5. Reproductive properties of rabbits (average) $(n=8)$.

\begin{tabular}{|c|c|c|}
\hline Parameters & Control & Experimental \\
\hline Fertility, in numbers & $11 \pm 0.35$ & $12 \pm 0.43$ \\
\hline Alive & $9 \pm 0.33$ & $11 \pm 0.42$ \\
\hline Dead & $2 \pm 0.51$ & $1 \pm 0.42$ \\
\hline Milk breeding, g & $2725.3 \pm 76.52$ & $2822.9 \pm 85.87$ \\
\hline $\begin{array}{c}\text { Survival of a rabbit cub } \\
\text { up to 21 days, \% }\end{array}$ & $93.5 \pm 0.16$ & $1.2 \pm 0.29$ \\
\hline $\begin{array}{c}\text { Deaths up to 4 months, } \\
\%\end{array}$ & $1.3 \pm 0.34$ & $96.6 \pm 0.65$ \\
\hline $\begin{array}{c}\text { Survival of a rabbit cub } \\
\text { up to 120 days, \% }\end{array}$ & $92.2 \pm 0.21$ & \\
\hline
\end{tabular}

At birth, the total number of rabbits in the control group was 88 heads, the total number of rabbits in the experimental group was 96 heads, while at the age of 120 days the rabbits survived 81 heads in the control group and 93 heads in the experimental group. There was no significant difference in the live weights of the rabbits at birth, but by 30 days of growth, the experimental rabbits were $14.17 \%$ or $80.11 \mathrm{~g}$ more than their counterparts in the control group.

At 45 days of the experiment, the experimental group of rabbits gained 150.11 grams, 512.04 grams at the age of 90 days, 850.11 grams at the age of 120 days, and 708.21 grams at the age of 150 days. While the growth of rabbits in both groups was observed to increase rapidly until 3 months of age, a decrease in growth was observed in subsequent months. Experimental data show that high weight gain can be achieved from rabbits bred by feeding young growing rabbits from birth to 3 months of age on the basis of an intensive full-value diet.

The table shows that the experimental rabbits grew rapidly up to 4 months of age. Through intensive feeding on a full-value ration, it is possible to gain 850.15 grams of excess weight from each rabbit compared to the control group, with an increase of 4100.65 grams by the age of 120 days (Table 6).

Table 6. Live weight growth dynamics of rabbits.

\begin{tabular}{|c|c|c|c|c|}
\hline Ages & Control & Experimental & Absolute growth & Relative growth \\
\hline New born & $69.71 \pm 0.19$ & $69.86 \pm 0.25$ & 0.15 & 0.20 \\
\hline 21 & $277.89 \pm 13.33$ & $285.21 \pm 11.71$ & 7.32 & 2.63 \\
\hline 30 & $565.18 \pm 5.22$ & $645.27 \pm 7.21$ & 80.11 & 14.17 \\
\hline 45 & $1198.46 \pm 7.56$ & $1348.56 \pm 5.37$ & 150.11 & 12.52 \\
\hline 60 & $1340.64 \pm 4.48$ & $1855.68 \pm 18.93$ & 512.04 & 38.42 \\
\hline 90 & $2891.63 \pm 19.21$ & $3367.14 \pm 53.43$ & 475.5 & 16.44 \\
\hline 120 & $3250.54 \pm 5.87$ & $4100.65 \pm 46.81$ & 850.11 & 26.15 \\
\hline 150 & $3855.29 \pm 28.59$ & $4563.50 \pm 48.75$ & 708.21 & 18.36 \\
\hline
\end{tabular}


In order to fully assess the growth of rabbits, body length and breast circumference were studied, which were the main indicators of rabbits at the time of slaughter. From the data obtained, it can be concluded that the body length of rabbits fed on a full-value ration averagely $5.73 \mathrm{~cm}$ in body length, $3.89 \mathrm{~cm}$ in circumference and $0.71 \%$ higher than in the control group (Table 7).

Table 7. Body size of 150-day-old rabbits, $\mathrm{cm}(\mathrm{n}=25)$.

\begin{tabular}{|c|c|c|}
\hline Body measurements & Control & Experimental \\
\hline Body length & $59.64 \pm 2.4$ & $65.01 \pm 1.9$ \\
\hline Chest circumference & $38.44 \pm 1.5$ & $42.33 \pm 2.1$ \\
\hline Density index & 64.6 & 65.31 \\
\hline
\end{tabular}

Meat productivity of rabbits was assessed on a scientific basis by studying the meat productivity of rabbits reared on the basis of a full-value ration. At the age of 150 days, based on the average weight of the groups, 4 rabbits were separated from each group and a control slaughter was performed. Rabbits fed on a full-value ration were found to be $14.99 \%$ more pre-slaughter weight than their peers fed on a farm-adopted ration. Similarly, their slaughter expenditure was found to be higher in the experimental group (61.38\%), indicating an abundance of muscle and fat tissue in the experimental rabbits.

The meat content was 6.71 for farm-fed rabbits and 7.461 for whole-grain rabbits. It was also found that the body weight of rabbits fed in the experimental group was 375.00 grams or $17 \%$ more than farm-fed rabbits (to the nearest 0.99 ). Note that the meat of rabbits in both groups was found to be group I. Chemical analysis and nutritional value of rabbit meat yielded the following results: Intensively bred rabbit meat was found to be soft, pale in color, and high in water, dry matter, protein, and fat, compared to farm-fed rabbits.

In our experiments, the protein content of rabbit meat fed on an intensive full-fledged ration was 10.84 compared to fat, and 10.75 on rabbit meat fed on a farm ration. The energy value increased by $20.78 \%$ due to the high content of fat and dry matter in the meat.

Intensive feeding of rabbits in a complete ration method has proven to be cost-effective. The main efficiency of feeding with this method in rabbits is that they are given in a very short time, not exceeding 130-150 days (Table 8). In this case, the experimental rabbits reach a live weight of 4-5 kg, meat weight $2.0-2.7 \mathrm{~kg}$. 1 head sold rabbit meat and skin sold at the same price, which was $1.2 \%$ higher than the control group.

Table 8. Economic efficiency.

\begin{tabular}{|c|c|c|c|c|c|}
\hline \multirow{2}{*}{$\#$} & \multirow{2}{*}{ Parameters } & \multicolumn{2}{|c|}{ 'Atoev Akbar' Sole Proprietor } & \multicolumn{2}{c|}{ 'Isaev Gulomkodir' Sole Proprietor } \\
\cline { 2 - 6 } & & Control & Experimental & Control & Experimental \\
\hline \multirow{2}{*}{1} & $\begin{array}{c}\text { Live weight before } \\
\text { slaughter, g }\end{array}$ & $3021 \pm 74.30$ & $3315 \pm 47.2$ & $3542 \pm 35.22$ & $3758 \pm 39.11$ \\
\hline 2 & Chest weight, g & $1526 \pm 53.11$ & $1717 \pm 28.14$ & $1920 \pm 34.01$ & $2168 \pm 24.89$ \\
\hline 3 & Slaughter expenses, \% & $50.5 \pm 0.12$ & $51.8 \pm 0.51$ & $54.2 \pm 1.51$ & $57.7 \pm 2.00$ \\
\hline 4 & Fillet, \% & $83.1 \pm 0.62$ & $84.7 \pm 0.25$ & $84.5 \pm 1.11$ & $85.0 \pm 0.89$ \\
\hline 5 & Fillet weight, g & $1268 \pm 48$ & $1454 \pm 35$ & $1622 \pm 21$ & $1843 \pm 17$ \\
\hline 6 & Bone, \% & $16.9 \pm 0.20$ & $15.3 \pm 0.15$ & $15.5 \pm 0.80$ & $15.0 \pm 0.74$ \\
\hline 7 & Bone weight, g & $258 \pm 21$ & $263 \pm 32$ & $268 \pm 5.95$ & $325 \pm 4.41$ \\
\hline 8 & Meat ratio & 4.9 & 5.5 & 6.1 & 5.8 \\
\hline 9 & Profitability level, \% & 74.4 & 96.2 & 119.4 & 147.8 \\
\hline
\end{tabular}


The net profit obtained when fed on the intensive full-fledged ration method was $48.6 \%$ higher than when fed on the farm ration. The rate of return was $19.1 \%$ in the control group and $43.8 \%$ in the experimental group.

\section{Conclusions}

When rabbits were fed an intensive complete diet, it had a positive effect on their productivity and biological properties. When rabbits and rabbits were fed in this way, it was found that their live weight was higher than $0.73 \mathrm{~kg}$.

The fertility of rabbits fed on the basis of intensive rations was $9.09 \%$ higher than that of rabbits in the control group, as well as the survival rate of rabbits in the experimental group up to 21 days was $97.8 \%$, and at 4 months - $96.6 \%$.

When rabbits were fed on an intensive diet for up to 4 months, they had a $26.15 \%$ increase in live weight compared to their peers in the control group, ie their live weight reached $4.10 \mathrm{~kg}$, which is $2.57 \mathrm{~kg}$ or $17.12 \%$ of their post-slaughter weight found to be higher than their peers.

The energy value of the meat yield of rabbits fed on intensive complete feeding technology was $1.13 \mathrm{MJ}$, while the ratio of protein to fat was 10.86 .

As a result of the intensive development of the muscle tissue of the rabbits during the growth period, the group of muscle tissue in the experimental rabbits at the age of 150 days in both methods increased by $9.6 \%$.

Rabbits in the experimental group consumed $4.21 \mathrm{~kg}$ of feed unit, or $24.7 \%$ less than in the control group, to gain $1 \mathrm{~kg}$ of live weight. It was found that the amount of hemoglobin in the blood of rabbits increased by $16.49 \%$ compared to the experimental group. But it turned out that this indicator is atrophic of the physiological norm. The level of profitability of rabbit meat production was 74.4 and $119.4 \%$ in rabbits fed on the farm ration, 96.2 and $147.8 \%$ in the intensive-ration ration.

As a result of adding soybean meal, meat and bone meal, premixes enriched with vitamins and macro-and micronutrients to the rabbit diet, it was found that the rabbits in the experimental group had a live weight of $0.73 \mathrm{~kg}$ higher than in the control group.

\section{References}

1. K. Kozioł, Z. Siudak, S. Pałka, M. Kmiecik, A. Otwinowska-Mindur, L. Migdał, J. Bieniek, Sci. Ann. Pol. Soc. Anim. Prod., 13, 55-60 (2017)

2. M. M. Abo Ghanima, A. H. Abd El-Aziz, A. Noreldin, M. Atta, S. Mousa, A. El-Far, Plos one, 15(6), e0234076 (2020)

3. M. Nasr, T. Abd-Elhamid, M. Hussein, Meat Science, 134, 150-157 (2017)

4. S. Li, Z. He, Y. Hu, H. Li, Italian Journal of Animal Science, 18(1), 1335-1344 (2019)

5. M. North, A. Dalle Zotte, L. Hoffman, South African Journal of Animal Science, 49(5), 815-823 (2019)

6. M. Senchenko, E. Pivovarova, G. Agapov, M. Petrović, V. Caro Petrović, D. RužićMuslić, N. Maksimović, Biotechnology in Animal Husbandry, 34(2), 259-267 (2019)

7. A. Lesnyak, Productivity and product quality of rabbits when adapting to various conditions of keeping in the Central Black Earth zone, PhD Thesis, Belgorod, 307 (2006)

8. A. Ageykin, Rabbit technology (practical manual), Krasnoyarsk, 89 (2009) 
9. V. Aleksandrov, Scientific bases of production technology for rabbit products, $\mathrm{PhD}$ thesis, 251 (2001)

10. T. Ikramov, Development of rabbit breeding in Uzbekistan (practical guide), Tashkent 145 (1983)

11. S. Kushakov, Rabbit Breeding, 1, 14-17 (1993) (in Uzbek)

12. A. Fadlilah, D. Rosyidi, A. Susilo, In IOP Conference Series: Materials Science and Engineering, 811(1), 012024 (2020)

13. N. I. Tinaev, Rabbit Breeding, 4, 22-25 (2004)

14. YU. Zhitnokova, Compound Rabbits, 8(21), 5-9 (2004)

15. D. Belichovska, K. Belichovska, Z. Pejkovski, Z. Uzunoska, Scientific journal "Meat Technology", 58(1), 10-15 (2017)

16. S. Suleman, S. A. Khan, M. H. Aziz, Turkish Journal of Veterinary and Animal Sciences, 44(4), 945-949 (2020)

17. A. KH. Kholmatov, Journal of Agribusiness, 5(148), 36-48 (2016) 